\title{
Effects of Different Dietary Approaches on Type 2 Diabetes Mellitus: A Review
}

\section{Dipan Samanta ${ }^{1 *}$, Amarendra Haldar ${ }^{2}$, Zeeshan Ali ${ }^{3}$, Jyothsna Volisha Cardoza ${ }^{3}$, Muhammad Rehan Arif ${ }^{4}$, Muhammad Qasim Ali ${ }^{5}$}

\author{
${ }^{1} J u n i o r$ Resident, Department of Obstetrics and Gynaecology, Dali University, Yunnan, China \\ ${ }^{2}$ Student, Department of Nutrition and Dietetics, Mount Carmel College (Autonomous), Bengaluru, India \\ ${ }^{3}$ Assistant Professor, Department of Physiotherapy Krupanidhi groups of institutions, College of Physiotherapy, \\ Bangalore, India \\ ${ }^{4}$ Institute of Food and Nutritional Sciences, PirMehr Ali Shah Arid Agriculture University Rawalpindi, Punjab, Pakistan \\ ${ }^{5}$ Institute of Food Science and Nutrition, University of Sargodha, Punjab, Pakistan
}

*Address for Correspondence: Dr. Dipan Samanta, Junior Resident, Department of Obstetrics and Gynaecology, Dali University, Yunnan-671000, China

E-mail: medblog18@rediffmail.com

Received: 11 Sep 2021/ Revised: 14 Nov 2021/ Accepted: 27 Dec 2021

\begin{abstract}
Type 2 diabetes (T2D) is a metabolic disorder that occurs due to various etiologies including lifestyle. One of the significant contributors in causing Type-2 diabetes is diet. For high-risk individuals, diet is way more significant in causing Type-2 diabetes. This present study discussed several published papers comprising of various food categories and their effects on type-2 diabetes or its role in causing the disorder. The study revealed the advantages of functional foods and their role in the prevention of T2D. The study has elaborated the outcome of T2D due to consumption of fats, carbohydrates, protein, dietary fibres, red meat, fried food, common beverages like carbonated drinks, and a few other foods. The authors also reviewed T2D from the aspect of religion, region, specific lifestyles, smoking and drinking habit and body weight. Overall, the study has successfully drawn a map of the spectrum of dietary role in T2D including its prevention, increasing the risk of T2D, its causation and affecting the outcome of the disorder.
\end{abstract}

Key-words: Diabetes mellitus, Glycaemicindex, Hyperglycaemia, Metabolic disorder, Type 2 diabetes

\section{INTRODUCTION}

Definition and epidemiology- Type 2 diabetes (T2D) is the most well-known and clinically significant metabolic issue which has turned into a worldwide contagion late and a serious medical burden since the past few years. According to global figures, there were about 382 million patients in $2013^{[1]}$, which is expected to reach 350 million by the year $2025^{[1,2]}$. The World Health Organization (WHO) characterizes diabetes as a disease that disrupts the normal metabolism of the body having

\section{How to cite this article}

Samanta D, Haldar A, Ali Z, Cardoza JV, Arif MR, Ali MQ. Effects of Different Dietary Approaches on Type 2 Diabetes Mellitus: A Review. SSR Inst. Int. J. Life Sci., 2022; 8(1): 2931-2939.

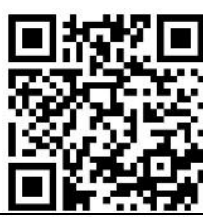

numerous etiology and presents conditions like persistent hyperglycaemia, which interferes with normal breakdown and assimilation of 3 basic and major components of food (carbohydrate, fat, and protein) because of deformities in either insulin production or functioning, or both ${ }^{[3]}$. Out of all forms of diabetes, type 2 is the most prevalent (around $90 \%$ ) ${ }^{[2]}$ and the rest $10 \%$ of patients have either type 1 diabetes (T1D), or its other uncommon types ${ }^{[4]}$. There are two main causes of T2D. They are defective pancreatic beta-cells working (responsible for insulin production); resistance towards insulin exhibited by peripheral tissue ${ }^{[5,6]}$. As about $~ 90 \%$ of patients suffering from T2D are also seen to be obese, the etiology of T2D gets frequently linked with foods consumed entirely for taste and flavour rather than for getting nutrition accompanied with inadequate energy expenditure ${ }^{[7]}$. There is a scope of compelling drugs that 
diminish hyperglycaemia in T2D patients, which are said to be the reason behind insulin emission or diminishing peripheral tissue Insulin Resistance ${ }^{[8]}$. In defiance of all this T2D presents lifelong impediments and is considered as the dominant cause of visual impairment, end-stage renal deterioration (leaving with only 2 last options for survival dialysis or transplant of the kidney), confiscation of lower appendages (up to $25 \%$ more than normal people) and cardiovascular diseases ${ }^{[3]}$.

Relationship of T2D with diet- The pervasiveness of T2D is expanding at a disturbing rate around the world, causing a huge expansion in premature bereavement, co-morbidity and expanded cost of healthcare ${ }^{[9]}$. The future forecasts are likewise miserable given that 1 of every 10 individuals present on the planet is estimated to be its sufferer by $2030{ }^{[10]}$. Normal determinants incorporate obesity, unbalanced eating rituals, sedentary lifestyle, hypertension, and family background of diabetes ${ }^{[9]}$. But studies have shown globally that if people with pre-diabetes and high-risk population concentrate on diet-change and carry out regular exercise, then there can be $58 \%$ reduction in risk of T2DM incidence rate as opposed to using metformin alone where only $28 \%$ risk reduction occurs when compared to controls [11-14]. This evidence lead to the necessity of exploring the precautionary and beneficiary role of healthy foods, which can be coined as functional foods (FnFs). FnFs are logically demonstrated to have potential medical advantages.

Functional Foods are all food sources that comprise biologically dynamic components and may be helpful in prevention/ delaying of numerous chronic illnesses like T2D, a parallel term to FnFs is "nutraceuticals" that alludes to components found in FnFs and is related to derivation and making them available to use ${ }^{[15]}$.

\section{Association of diabetes with three principal forms of foods}

Fats- Diminishing the ingestion of saturated fat (SF) and cholesterol with intention of bringing down diminishing plasma lipid levels has been a practically all-inclusive solution for individuals with a risk of diabetes. There has been debate regarding what should supersede SFcarbohydrate $(\mathrm{CHO})$ or monounsaturated fat (MUFAs); since evidence from studies proposed that foods containing MUFAs might be better than low-fat and high CHO ones ${ }^{[16]}$.
Diet with high MUFA can be replaced by a Mediterranean diet comprising of vegetables, coarse and whole grains, fruits, nuts, and olive oil and keep a strict check on the level of SF from meat, poultry, and dairy items ${ }^{[17]}$. Several investigations have illustrated that the Mediterranean diet regulates plasma lipid levels without causing unfavourable changes in triglyceride and HDL cholesterol $^{[18]}$.

Preclinical information supports the idea that high incorporation of MUFA, (like oleate), may exert physiological benefits. It has been proved that exposure of pancreatic islets to the excess amount of fatty acids diminishes insulin discharge ${ }^{[19]}$, and saturated fatty acid (SFAs) (like palmitate) aggravates cell death, while oleate has a defensive/ neutral impact ${ }^{[20]}$. Moreover, although persistently raised circulating fatty acids cause insulin resistance (Insulin Resistance), this impact is by all accounts more articulated with SFAs than with MUFA ${ }^{[21]}$. In this manner, current evidence from in vitro and animal studies upholds the replacement of MUFA for SFAs in diabetic people ${ }^{[22]}$.

Thus, living with T2D on a high MUFA diet are a better option than traditional low-fat, high-CHO foods with similar advantageous consequences on body weight, body composition, cardiovascular danger factors, and glycemic control. Also, study has shown MUFA rich diet has done wonders on T2D even in Non-Mediterranean locales ${ }^{[23]}$.

Carbohydrates- It has been discovered from many explorations that in the population suffering from diabetes, glycaemic control showed signs of improvement as carbohydrate intake in daily food regime got enhanced proving that earlier studies ${ }^{[24]}$ in this context stand true that a diet composed of relatively high carbohydrate is beneficial in diabetes, in contrast to a low (typically around $40 \%$ of total energy) carbohydrate diet ${ }^{[25]}$. Yet another conclusion was that only those high carbohydrate foods that are also impregnated with dietary fibre ${ }^{[26,27]}$ will lead to better glycaemic control. Two latest reviews, the former speaking of effects of viscous fibre [28], and the latter which was an umbrella review did not have any new insights of relevance ${ }^{[29]}$. However, these benefits were only apparent, when the carbohydrate-containing foods were rich in dietary fibre ${ }^{[26,27]}$. There have been 2 more recent reviews, one related to the effects of viscous 
fibre $^{[28]}$, and the other was an umbrella review that did not provide any new analyses ${ }^{[29]}$.

Proteins- Legumes (including soy foods) have remarkable beneficiary dietary elements being low in glycemic index, full of nutritional ingredients like proteins etc., and the icing is their antibody-diabetic potential; thus validates daily ingestion of legumes and soy products for prophylaxis and management of T2D ${ }^{[30,31]}$. Although this school of thought has dual viewpoints: few explorations reportage builds an inverse connotation amid legumes/soy diet and the perils of T2D ${ }^{[32-35]}$; while a mosaic of others testifying a null ${ }^{[36-42]}$ or a positive ${ }^{[22,23]}$ connection.

A meta-analysis ${ }^{[43]}$ concluded that the amount of legume in the diet has no direct linkage with T2D risks and that different varieties of soy foods have a variable impact; but it also recommended that augmenting a normal food course with $10 \mathrm{~g}$ soy protein and $10 \mathrm{mg}$ soy is flavone can result in $9 \%$ and $4 \%$ reduced chances of T2D, respectively, regardless of little evidence in favour ${ }^{[43]}$.

Soy milk a kind of liquid food with added sugar may lose its antibody diabetic potency because sweetened beverages are notorious for risk of type 2 diabetes ${ }^{[4]}$, thus confirming findings of a cohort study that declared that unsweetened soy is inversely and its sugaredcounterpart is directly linked to T2D ${ }^{[33]}$.

\section{Other important foods}

Dietary fibre- A Study that incorporated 14 RCTs (Randomized controlled trials) (covering all three categories of people viz. healthy, pre-diabetic, and diabetic) unearthed that intake of both insoluble or soluble fibre, when gets scoffed with diets that compose plentiful of coarse grains and vegetables, and also vegan followers showed honed glucose metabolism and the upsurge insensitivity towards insulin. The best improvement in blood lipids, body weight, and Hemoglobin $A_{1 c}$ (HbA1c) level happened in members People who religiously followed a low-fat, plant-based eating regime pictured overwhelming restoration related to blood lipids, body weight, and HbA1c levels. Meals laden with grains, veggies and both kinds of fibres were equally beneficial for diabetic and healthy subjects. Glucose equilibrium and insulin sensitivity were rather better exhibited by people on a more plant-based diet rather than a conventional diet ${ }^{[45]}$. It has been claimed that more consumption of dietary fibre has a direct linkage with the reduced rate of premature mortality and chances of acquiring diverse kinds of non-communicable diseases. Thus it suggested to people of these 3 categories (pre-diabetes and having either type of diabetes) that they should have up to $35 \mathrm{~g}$ daily dose of fibre and this can easily be achieved by preferring whole grains over processed ones ${ }^{[46]}$.

Red meat and Fried food- Having more amount of red meat, desserts and fat-laden food will eventually increase the risk of Insulin Resistance (IR) and T2DM ${ }^{[47]}$. And, a converse relationship is seen between consuming vegetables and T2DM as utilization of leafy foods (as they are laden with nutrients, fibre and antioxidants) might restrict the advancement of $\mathrm{T} 2 \mathrm{D}$, by forming a defensive obstruction against the diseases ${ }^{[48]}$. Red meat and excess oil/fat cooked foods are a common feature of a diet of males when contrasted with females. Also, they have been seen to take in more daily rice-helpings than their female counterparts ${ }^{[49]}$. A contrasting study on Japanese ladies uncovered that a high amount of white rice was related to an increased risk of T2DM ${ }^{[50]}$.

\section{Common beverages}

Carbonated drinks- Novel studies have proposed a connection between the ingestion of soda pops with obesity and diabetes, as they come loaded with a high concentration of fructose corn syrup that causes blood rise of glucose levels and BMI to hazardous levels. It has also come to the limelight that expressed that diet sodas contain glycated synthetics that particularly promote Insulin Resistance ${ }^{[51]}$.

Tea- Epidemiological investigations have exhibited different positive relationships amid daily usage of herbal tea as a good prophylactic measure in T2D ${ }^{[52,53]}$. Herbal teas including dark and green concoctions and yet another variety of yerba maté, (native to South America) have spread their wings to North America, and portions of Europe and the Levant ${ }^{[53,54]}$. Populaces who are at diabetes risk may essentially gain from the utilization of locally available natural tea ingestions like Mauritian people (potential suspects of T2D) seem to benefit from their teas (high in polyphenolics) ${ }^{[55]}$.

\section{Other miscellaneous foods}

$>$ A systematic review and meta-analysis (7 trials, 350 respondents) confirmed that the addition of pomegranate in the daily diet of diabetic associates 
laid no remarkable effect on "metabolic status and oxidative stress biomarkers" of the volunteers, also no publication bias was inked ${ }^{[56]}$.

$>$ There has been observed a linkage amid deficiency of vitamin $D$ and T2D but there is no apparent clarity that whether its supplements are capable of diminishing chances of acquiring T2D. But in people with pre-diabetes, Vit-D supplements condenses the possibility of T2D and proliferate the chances of reversion from pre-diabetes to normoglycemia. This retreat might be limited to those subjects who were otherwise not obese ${ }^{[57]}$.

$>$ Studies have revealed that regular incorporation of walnut in diet may enhance serum leptin and adiponectin. But showcased no changes in fasting blood glucose (FBG) or insulin and glycatedhaemoglobin (HbA1c) levels thus has no impact in improving glycemic biomarkers ${ }^{[58]}$.

\section{Reviewing T2DM from various aspects}

Religion specific study on T2D- Practicing the ritual of fasting during the month of Ramadan is one of the five mainstays of Islam ${ }^{[59,60]}$ and requires shunning eating, drinking and the utilization of oral or parenteral drugs from dawn to nightfall for 29-30 continuous days once per year ${ }^{[59,61]}$. It is prohibited to patients with Type 1 diabetes and restricted to an enormous extent of patients with T2D ${ }^{[62,63]}$. But, a new review of 38,000 patients with diabetes from 39 nations found that $39 \%$ went fasting during Ramadan, other ones supported it by stating that $43 \%$ of patients with type 1 diabetes and $79 \%$ with type 2 diabetes kept fast during Ramadan ${ }^{[64,65]}$. Fasting might prompt prescription non-adherence [61] and complexities including lack of hydration, hyperglycemia, diabetic ketoacidosis [59,61,64] and hypoglycemia ${ }^{[66]}$.

While a few examinations have shown no effect of this religious fasting on factors related to metabolism in patients with diabetes ${ }^{[67]}$, different other investigations have shown an improvement in glycemia and lipids in those have controlled baseline-level of sugar; yet the condition was deteriorating in patients with poor glycemic control ${ }^{[68]}$. A few examinations have exhibited a huge decrease ${ }^{[69]}$ while others have shown no huge change in $\mathrm{HbA1C}$, weight or $\mathrm{BMI}^{[70]}$.

Educative sessions on how to fast while being diabetic were an advantage in Type 1 diabetes ${ }^{[71]}$ and lesser significant in Type 2 diabetes ${ }^{[72]}$. This one-of-a-kind detailed meta-analysis exhibits that Ramadan explicit knowledge sharing gives benefits by tending to lower $\mathrm{HbA1C}$ and LDL; causing body weight and TG to shoot up; while remaining safe with null impact on TC, HDL, blood pressure or hypoglycemia ${ }^{[73]}$.

Region-specific diet- A special kind of diet called Mediterranean diet (MD) has become the real hot potato in the medical field as it comprises of high consumption of plant-based foods, moderate quantity of fish and dairy items, and least intake of red meat and red wine ${ }^{[74]}$. In it, the salt intake can be replaced by the utilization of spices ${ }^{[75]}$. Due to its potential benefits, MD is flowing across international borders in non-Mediterranean areas as well [76].

Main eatables of the Mediterranean diet - like plantbased salads, fishes with high oil content, olive oil, are a few components of FnFs and nutraceuticals that are embedded with "polyphenols (PPs), terpenoids, flavonoids, alkaloids, sterols, pigments, and unsaturated fatty acids". PPs and associated herbs rich in it like coffee, tea (both green and black) and yerba mate have exhibited promising results in decreasing $\mathrm{CH}$ and $\mathrm{FBS}$ levels, taking care of various metabolic and microvascular mechanisms and acting as anti-inflammatory and anti-oxidative agents in people suffering from $T 2 D$ or those, who are much prone to it ${ }^{[77]}$.

Lifestyle specific-various patterns and incidences of T2D- It has now been unveiled that embracing a fit and active way of life (for example keeping a sound body weight, following a balanced eating routine, regular exercise, abstaining from smoking and keeping away from unsafe liquor drinking) is a 'best purchase' mediation for keeping T2D at bay ${ }^{[78]}$. Many large Randomized Controlled Trials validate that thoughtful and well-planned life leading ways can be successful for the avoidance of T2D ${ }^{[79]}$.

Comparative study ${ }^{[80]}$ has concluded that vivacious people with a lithesome life would have a $75 \%$ lower hazard of occurrence T2D than most torpid and sluggard individuals, and it applies to populaces from various financial foundations and benchmark attributes. Also, such a lifestyle has been related with $56 \%, 49 \%, 31 \%$ and $52 \%$ lesser deaths due to all causes, CVD, cancer and chances of occurrence of CVD in T2D individuals ${ }^{[80] .}$ Excessive consumption of salt and sugar or less consumption of antioxidant vitamins like vitamin C play 
an important role in causing hypertension and diabetes

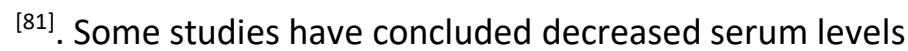
of vitamin $C$ in hyperglycaemic individuals. These studies have also found that anti-oxidants like Vitamin $C$ has resulted in the free radical formation and has shown beneficial effects on glycaemic status, when vitamin $C$ is given therapeutically ${ }^{[82]}$.

Smoking and drinking- Smoking is only evil gets yet another proof as current smokers have been seen to experience a $37 \%$ higher danger of T2D contrasted with never smokers ${ }^{[83]}$. But alcohol gets a narrow escape here as it was found that moderate drinking (10-14 g liquor each day) is related to an $18 \%$ lower hazard of T2D contrasted to teetotalers ${ }^{[84]}$.

Bodyweight- The most grounded affiliation was seen between body weight and occurrence type 2 diabetes: overweight and people struck with obesity showed a $133 \%$ and $510 \%$ higher danger of T2D, paralleled, with their equal weight partners ${ }^{[85]}$.

\section{CONCLUSIONS}

The study has elaborated on the effects of various diets on Type 2 Diabetes. The study reviewed that a significant number of patients with type 2 diabetes are obese individuals. Long-standing type 2 diabetes in obese individuals also leads to various outcomes like renal diseases, visual impairment, etc. It is found that there may be 1 in every 10 individuals with T2D by the year 2030. Along with drug therapies, there is an urgent need to explore the beneficial role of functional foods in T2D. The study brought forward that the Mediterranean diet has a beneficial role in the maintenance of plasma lipid levels. It has been suggested to diabetic people for increasing diets with Saturated Fatty Acids in place of MUFA laden diet. Diabetic people are also suggested to include 35 grams of fibre in their daily diet and should prefer whole grain over processed ones.

Overall, the study elaborated the dietary strategy in the management of type- 2 diabetes from various aspects which can also be considered as one of the most significant inclusions in the treatment plan of T2D.

\section{CONTRIBUTION OF AUTHORS}

Research concept- Dipan Samanta

Research design- Dipan Samanta, Amarendra Haldar, Zeeshan Ali, Jyothsna Volisha Cardoza

Supervision- Dipan Samanta
Literature search- Zeeshan Ali, Jyothsna Volisha Cardoza

Writing article- Zeeshan Ali, Jyothsna Volisha Cardoza

Critical review- Dipan Samanta, Zeeshan Ali, Jyothsna

Volisha Cardoza

Article editing- Dipan Samanta

Final approval- Dipan Samanta

\section{REFERENCES}

[1] Verma $M$, Alam $R$, Mobin $M$. Review on Malondialdehyde and Superoxide dismutase levels in patients of Type 2 Diabetes Mellitus with Retinopathy and without Retinopathy. Int J Life Sci Sci Res., 2015; 1: 52-57.

[2] Ozougwu JC, Obimba KC, Belonwu CD, Unakalamba $\mathrm{CB}$. The pathogenesis and pathophysiology of type 1 and type 2 diabetes mellitus. J Physiol Pathophysiol., 2013; 4: 46-57. doi: 10.5897/JPAP2013.0001.

[3] Thompson A, Kanamarlapudi V. Type 2 Diabetes mellitus and glucagon like peptide-1 receptor signaling. Clin Exp Pharmacol., 2013; 1: 3.

[4] Maahs DM, West NA, Lawrence JM, Mayer-Davis EJ. Chapter 1: Epidemiology of Type-1 Diabetes. Endocrinol Metab Clin North Am., 2010; 39(3): 48197. doi: 10.1016/j.ecl.2010.05.011.

[5] Kahn SE, Cooper ME, Del Prato S. Pathophysiology and treatment of type 2 diabetes: perspectives on the past, present, and future. Lancet, 2014; 383(9922): 1068-83. doi: 10.1016/S01406736(13)62154-6.

[6] Leahy JL. Pathogenesis of Type 2 Diabetes Mellitus. Arch Med Res., 2005; 36(3): 197-209. doi: 10.1016/j.arcmed.2005.01.003.

[7] Chen L, Magliano DJ, Zimmet PZ. The worldwide epidemiology of type 2 diabetes mellitus (mdash) present and future perspectives. Nat Rev Endocrinol., 2012; 8(4): 228-36. doi: 10.1038/nren do.2011.183.

[8] Raz I. Guideline approach to therapy in patients with newly diagnosed type 2 diabetes. Diabetes Care, 2013; 36(S2): S139-44. doi: 10.2337/dcS13-2035.

[9] World Health Organization (WHO). Global Report on Diabetes. Available online: http://www.who.int/ diabetes/global-report/en/, 2016.

[10]IDF. Diabetes Atlas, 2015-7 $7^{\text {th }}$ Edition. Available online: http://www.diabetesatlas.org/.

[11] Knowler WC, Barrett-Connor E, Fowler SE, Hamman RF, Lachin JM, et al., Diabetes Prevention Program Research. Reduction in the incidence of type 2 
diabetes with lifestyle intervention or metformin. $\mathrm{N}$ Engl J Med., 2002: 346: 393-403.

[12]Tuomilehto J, Lindstrom J, Eriksson JG, Valle TT, Hamalainen $\mathrm{H}$, et al. Finnish Diabetes Prevention Study Group. Prevention of type 2 diabetes mellitus by changes in lifestyle among subjects with impaired glucose tolerance. N Engl J Med., 2001; 344: 134350.

[13]Pan XR, Li GW, Hu YH, Wang, JX, Yang WY, et al. Effects of diet and exercise in preventing NIDDM in people with impaired glucose tolerance. The Da Qing IGT and Diabetes Study. Diabetes Care, 1997; 20: 537-44.

[14]Ramachandran A, Snehalatha C, Mary S, Mukesh B, Bhaskar, AD, et al. Indian Diabetes Prevention Programme (IDPP). The Indian Diabetes Prevention Programme shows that lifestyle modification and metformin prevent type 2 diabetes in Asian Indian subjects with impaired glucose tolerance (IDPP-1). Diabetologia., 2006; 49: 289-97.

[15]Alkhatib A, Tsang C, Tiss A, Bahorun T, Arefanian H, et al. Functional foods and lifestyle approaches for diabetes prevention and management. Nutr., 2017; 9(12): 1310.

[16]Franz MJ, Bantle JP, Beebe CA, Brunzell JD, Chiasson $\mathrm{JL}$, et al. Evidence based nutrition principles and recommendations for the treatment and prevention of diabetes and related complications. Diabetes Care, 200225: 148-98.

[17]Verma M, Verma P, Parveen S, Dubey K. Comparative Study of Lipid Profile Levels in Vegetarian and NonVegetarian Person. Int J Life SciScienti Res, 2015; 1: 89-93.

[18]Garg A. High-monounsaturated-fat diets for patients with diabetes mellitus: a meta-analysis. Am J Clin Nutr., 1998; 67(S3): 577-82.

[19]Zhou YP, Grill VE. Long-term exposure of rat pancreatic islets to fatty acids inhibits glucoseinduced insulin secretion and biosynthesis through a glucose fatty acid cycle. J Clin Invest., 1994; 93: 87076.

[20]Maedler K, Oberholzer J, Bucher P, Spinas GA, Donath MY. Monounsaturated fatty acids prevent the deleterious effects of palmitate and high glucose on human pancreatic beta-cell turnover and function. Diabetes, 2003; 52: 726-33.
[21]Chavez JA, Summers SA. Characterizing the effects of saturated fatty acids on insulin signaling and ceramide and diacylglycerol accumulation in 3T3-L1 adipocytes and $\mathrm{C} 2 \mathrm{C} 12$ myotubes. Arch Biochem Biophys., 2003; 419: 101-09.

[22]Boden G. Free fatty acid and insulin secretion in humans. CurrDiab Rep., 2005; 5: 167-248.

[23]Brehm BJ, Lattin BL, Summer SS, Boback JA, Gilchrist, $\mathrm{GM}$, et al. One-year comparison of a highmonounsaturated fat diet with a high-carbohydrate diet in type 2 diabetes. Diabetes care, 2009; 32(2): 215-20.

[24] Kempner W, Peschel RL, Schlayer C. Effect of rice diet on diabetes mellitus associated with vascular disease. Postgraduate Med., 1958; 24(4): 359-71.

[25]Truswell AS, Thomas BJ, Brown AM. Survey of dietary policy and management in British diabetic clinics. BMJ. 1975; 4(5987): 7-11.

[26] Simpson HC, Simpson RW, Lousley S, Carter RD, Geekie $\mathrm{M}$, et al. A high carbohydrate leguminous fibre diet improves all aspects of diabetic control. Lancet, 1981; 1(8210): 1-5.

[27]Mann J. Lines to legumes: changing concepts of diabetic diets. Diabetic Medicine, 1984; 1(3): 191-8.

[28]Jovanovski E, Khayyat R, Zurbau A, Komishon A, Mazhar $N$, et al. Should Viscous Fiber Supplements Be Considered in Diabetes Control? Results from a Systematic Review and Meta-analysis of Randomized Controlled Trials. Diabetes Care, 2019.

[29]McRae MP. Dietary Fiber Intake and Type 2 Diabetes Mellitus: An Umbrella Review of Meta- analyses. J Chiropractic Med., 2018; 17(1): 44-53.

[30]American Diabetes Association. Nutrition recommendations and interventions for diabetes: a position statement of the American Diabetes Association. Diabetes Care, 2007; 30: S48-65.

[31]Mann JI, De Leeuw I, Hermansen K, Karamanos B, Karlstrom B, et al. Evidence-based nutritional approaches to the treatment and prevention of diabetes mellitus. Nutr Metab Cardiovasc Dis., 2004; 14: 373-94.

[32]Villegas R, Gao YT, Yang G, Li HL, Elasy TA, et al. Legume and soy food intake and the incidence of type 2 diabetes in the Shanghai Women's Health Study. Am J Clin Nutr., 2008; 87: 162-67.

[33]Mueller NT, Odegaard AO, Gross MD, Koh WP, Yu $M C$, et al. Soy intake and risk of type 2 diabetes 
mellitus in Chinese Singaporeans. Eur J Nutr., 2012, 51: 1033-40.

[34]Cosiales P, Corella D, Estruch R, Fito M, Serra-Majem $L$, et al. Legume consumption is inversely associated with type 2 diabetes incidences in adults: a prospective assessment from the PREDIMED study. ClinNutr., 2017; 37: 906-13.

[35]Konishi K, Wada K, Yamakawa M, Goto Y, Mizuta F, et al. Dietary soy intake is inversely associated with risk of type 2 diabetes in Japanese women but not in men. J Nutr., 2019; 149: 1208-14.

[36]Meyer K, Kushi L, Jacobs DR Jr, Slavin J, Sellers T, et al. Carbohydrates, dietary fiber, and incident type 2 diabetes in older women. Am J ClinNutr 2000; 71: 921-30.

[37]Hodge AM, English DR, O'Dea K, Giles GG. Glycemic index and dietary fiber and the risk of type 2 diabetes. Diabetes Care, 2004; 27: 2701-06.

[38]Liu S, Serdula M, Janket SJ, Cook NR, Sesso HD, et al. A prospective study of fruit and vegetable intake and the risk of type 2 diabetes in women. Diabetes Care, 2004; 27: 2993-96.

[39]Nanri A, Mizoue T, Takahashi Y, Kirii K, Inoue M, et al. Soy product and isoflavone intakes are associated with a lower risk of type 2 diabetes in overweight Japanese women. J Nutr., 2010; 140: 580-86.

[40]Ericson U, Sonestedt E, Gullberg B, Hellstrand S, Hindy $G$, et al. High intakes of protein and processed meat associate with increased incidence of type 2 diabetes. Br J Nutr., 2013; 109: 1143-53.

[41]Tatsumi Y, Morimoto A, Deura K, Mizuno S, Ohno Y, et al. Effects of soybean product intake on fasting and postload hyperglycemia and type 2 diabetes in Japanese men with high body mass index: the Saku Study. J Diabetes Investig., 2013; 4: 626-33.

[42]Ding M, Pan A, Manson JE, Willett WC, Malik V, et al. Consumption of soy foods and isoflavones and risk of type 2 diabetes: a pooled analysis of three US cohorts. Eur J ClinNutr., 2016; 70: 1381-87.

[43]Tang J, Wan $\mathrm{Y}$, Zhao $\mathrm{M}$, Zhong $\mathrm{H}$, Zheng JS, et al. Legume and soy intake and risk of type 2 diabetes: $A$ systematic review and meta-analysis of prospective cohort studies. The American journal of clinical nutrition, 2020; 111(3): 677-88.

[44]Imamura F, O'Connor L, Ye Z, Mursu J, Hayashino Y, et al. Consumption of sugar sweetened beverages, artificially sweetened beverages, and fruit juice and incidence of type 2 diabetes: systematic review, meta-analysis, and estimation of population attributable fraction. BMJ, 2015; 35: h3576.

[45]Wolfram T, Ismail-Beigi F. Efficacy of high-fiber diets in the management of type 2 diabetes mellitus. Endocrine practice, 2011; 17(1): 132-42.

[46]Reynolds AN, Akerman AP, Mann J. Dietary fibre and whole grains in diabetes management: Systematic review and meta-analyses. PLoS medicine, 2020; 17(3): e1003053.

[47] Panagiotakos DB, Tzima N, Pitsavos C, Chrysohoou C, Papakonstantinou $\mathrm{E}$, et al. The relationship between dietary habits, blood glucose and insulin levels among people without cardiovascular disease and Type 2 diabetes. Rev Diabet Stud., 2005; 2: 208-15.

[48]Villegas R, Shu XO, Gao YT, Yang G, Elasy T, et al. Vegetable but not fruit consumption reduces the risk of Type 2 diabetes in Chinese women. J Nutr., 2008; 138: 574-80.

[49]Mohieldein AH, Alzohairy $M$, Hasan M. Risk estimation of Type 2 diabetes and dietary habits among adult Saudi Non-diabetics in Central Saudi Arabia. Glob J Health Sci., 2011; 3:123.

[50]Nanri A, Mizoue T, Noda M, Takahashi Y, Kato M, et al. Rice intake and Type 2 diabetes in Japanese men and women: The Japan public health center-based prospective study. Am J ClinNutr., 2010; 92:1468-77.

[51]Assy N, Nasser G, Kamayse I, Nseir W, Beniashvili Z, et al. Soft drink consumption linked with fatty liver in the absence of traditional risk factors. Can J Gastroenterol., 2008; 22:811-16.

[52]Zheng XX, Xu YL, Li SH, Hui R, Wu YJ, et al. Effects of green tea catechins with or without caffeine on glycemic control in adults: A meta-analysis of randomized controlled trials. Am. J. Clin. Nutr., 2013; 97: 750-62.

[53] Iso H, Date C, Wakai K, Fukui M, Tamakoshi A. The relationship between green tea and total caffeine intake and risk for self-reported type 2 diabetes among Japanese adults. Ann. Intern. Med., 2006; 144: 554-62.

[54]Heck Cl, de Mejia EG, Yerba. Mate Tea (Ilex paraguariensis): A comprehensive review on chemistry, health implications, and technological considerations. J Food Sci., 2007; 72: R138-51.

[55]Bahorun T, Luximon-Ramma A, Gunness TK, Sookar $D$, Bhoyroo S, et al. Black tea reduces uric acid and C- 
reactive protein levels in humans susceptible to cardiovascular diseases. Toxicol., 2010; 278: 68-74.

[56]Jandari S, Hatami E, Ziaei R, Ghavami A, Yamchi AM. The effect of pomegranate (Punica granatum) supplementation on metabolic status in patients with type 2 diabetes: A systematic review and metaanalysis. Complementary Therapies in Medicine, 2020; 52: 102478.

[57]Zhang Y, Tan H, Tang J, Li J, Chong W, et al. Effects of vitamin D supplementation on prevention of type 2 diabetes in patients with prediabetes: a systematic review and meta-analysis. Diabetes Care, 2020; 43(7): 1650-58.

[58]Alam R, Verma M, Verma P. Glycated Hemoglobin as a Dual Biomarker in Type 2 Diabetes Mellitus Predicting Glycemic Control and Dyslipidemia Risk. Int J Life Sci Scienti. Res., 2015; 1: 62-65.

[59]Alabbood MH, Ho KW, Simons MR. The effect of Ramadan fasting on glycaemic control in insulin dependent diabetic patients: a literature review. Diabetes Metab Syndr., 2017; 11(1): 83-87.

[60]International Diabetes Federation (IDF). Diabetes and Ramadan: Practical Guidelines 2016. Available from: https://www.idf.org/e-library/guidelines/87diabetes-andramadan-practical-25.

[61]Abolaban H, Al-Moujahed A. Muslim patients in Ramadan: A review for primary care physicians. Avicenna J Med., 2017; 7(3): 81-87.

[62]Hassanein M, Al-Arouj M, Hamdy O, Bebakar WMW, Jabbar $A$, et al. Diabetes and ramadan: practical guidelines. Diabetes Res Clin Pract., 2017; 126: 30316.

[63]Bragazzi NL, Briki W, Khabbache H, Rammouz I, Mnadla $S$, et al. Ramadan fasting and infectious diseases: a systematic review. J Infect Dev Ctries., 2015; 9(11): 1186-94.

[64]Adnan Z. Type 2 diabetic patients fasting on ramadan in israel. Isr Med Assoc J., 2017; 19(5): 269-74.

[65]Salti I, Benard E, Detournay B, Bianchi-Biscay M, Le Brigand $C$, et al. A population-based study of diabetes and its characteristics during the fasting month of Ramadan in 13 countries: results of the epidemiology of diabetes and Ramadan 1422/2001 (EPIDIAR) study. Diabetes Care, 2004; 27(10): 230611.

[66]Jabbar A, Hassanein M, Beshyah SA, Boye KS, Yu M, et al. CREED study: hypoglycaemia during Ramadan in individuals with Type 2 diabetes mellitus from three continents. Diabetes Res Clin Pract., 2017; 132:19-26.

[67]Bouguerra RBSC, Belkadhi A, Jabrane H, Beltaifa L, Ben Rayana $C$, et al. Metabolic control and plasma lipoprotein during Ramadan fasting in non-insulindependent diabetes. Istanbul, Turkey: Second International Congress on Health and Ramadan, December 1-3, 1997; pp. 1997.

[68]Bouguerra R, Jabrane J, Maatki C, Ben Salem L, Hamzaoui J, et al. Ramadan fasting in type 2 diabetes mellitus. Ann Endocrinol., 2006; 67(1): 54-59.

[69]Bravis V, Hui E, Salih S, Mehar S, Hassanein M, et al. Ramadan education and awareness in diabetes (READ) programme for Muslims with type 2 diabetes who fast during Ramadan. Diabet Med., 2010; 27(3): 327-31.

[70]Ahmedani MY, Alvi SF, Haque MS, Fawwad A, Basit A. Implementation of Ramadan-specific diabetes management recommendations: a multi-centered prospective study from Pakistan. J Diabetes Metab Disord., 2014; 13(1): 37.

[71]Walker GS, Chen JY, Hopkinson H, Sainsbury CAR, Jones GC. Structured education using Dose Adjustment for Normal Eating (DAFNE) reduces longterm HbA1c and HbA1c variability. Diabet Med., 2018; 35(5): 745-49.

[72]Al-Arouj M, Assaad-Khalil S, Buse J, Fahdil I, Fahmy $M$, et al. Recommendations for management of diabetes during Ramadan: update 2010. Diabetes Care, 2010; 33 (8): 1895-902.

[73] Gad H, Al-Muhannadi H, Purra H, Mussleman, P, Malik RA. The effect of Ramadan focused education on patients with type 2 diabetes: A systematic review and meta-analysis. Diabetes Res Clin Pract., 2020; 162: 108122.

[74]Martinez-Gonzalez MA, Garcia-Arellano A, Toledo E, Salas-Salvado J, Buil-Cosiales $P$, et al. A 14-item Mediterranean diet assessment tool and obesity indexes among high-risk subjects: The PREDIMED trial. PLOS ONE, 2012; 7: e43134.

[75] Esposito K, Maiorino MI, Bellastella G, Panagiotakos DB, Giugliano D. Mediterranean diet for type 2 diabetes: Cardiometabolic benefits. Endocrine, 2017; 56: 27-32. 
[76]Alkhatib A, Klonizakis M. Effects of exercise training and Mediterranean diet on vascular risk reduction in post-menopausal women. Clin Hemorheol Microcirc., 2014; 57: 33-47.

[77]Klein S, Sheard NF, Pi-Sunyer X, Daly A, Wylie-Rosett $\mathrm{J}$, et al. Weight management through lifestyle modification for the prevention and management of type 2 diabetes: rationale and strategies. Diabetes Care, 2004; 27: 2067-73.

[78]Zheng $\mathrm{Y}$, Ley SH, Hu FB. Global aetiology and epidemiology of type 2 diabetes mellitus and its complications. Nat Rev Endocrinol., 2018; 14(2): 8898. doi: 10.1038/nrendo.2017.151.

[79]Gong $Q$, Zhang $P$, Wang J, et al. Morbidity and mortality after lifestyle intervention for people with impaired glucose tolerance: 30-year results of the $\mathrm{Da}$ Qing Diabetes Prevention Outcome Study. Lancet Diabetes Endocrinol,, 2019; 7(5): 452-61. doi: 10.1016/S2213-8587(19)30093-2.

[80]Zhang Y, Pan XF, Chen J, Xia L, Cao A, et al. Combined lifestyle factors and risk of incident type 2 diabetes and prognosis among individuals with type 2 diabetes: a systematic review and meta-analysis of prospective cohort tudies. Diabetologia, 2020; 63(1): 21-33.
[81]Singh S, Verma MK, Tripathi P, Durgesh S. Study of Oxidant (MDA) and Antioxidants (SOD \& Vitamin E) in Hypertensive Patients and Normotensive Individuals. Int J Life Sci Scienti Res., 2016; 2(1): 9-14.

[82]Tripathi P, Verma MK, Shankar TS, Singh S. Comparative Study of Malondialdehyde and Vitamin $C$ in Type 2 Diabetes Mellitus and Non Diabetic Individuals. Int J Life Sci Scienti Res., 2016; 2(1): 3136.

[83]Pan A, Wang $\mathrm{Y}$, Talaei M, Hu FB, Wu T. Relation of active, passive, and quitting smoking with incident diabetes: a meta-analysis and systematic review. Lancet Diabetes Endocrinol., 2015; 3(12): 958-67. doi: 10.1016/S2213-8587(15)00316-2.

[84]Knott C, Bell S, Britton A. Alcohol consumption and the risk of type 2 diabetes: a systematic review and dose-response meta-analysis of more than 1.9 million individuals from 38 observational studies. Diabetes Care, 2015; 38(9): 1804-12. doi: 10.2337/dc15-0710.

[85]Cloostermans L, Wendelvos W, Doornbos G, et al. Independent and combined effects of physical activity and body mass index on the development of type 2 diabetes-a meta-analysis of 9 prospective cohort studies. Int J Behav Nutr Phys Act., 2015; 12(1): 147. doi: 10.1186/s12966-015-0304-3. 